\title{
How I treat obesity and obesity related surgery in patients with chronic myeloid leukemia: an outcome of an ELN project.
}

\author{
mohamed yassin ${ }^{1}$, Nancy Kassem ${ }^{1}$, and Rola Ghassoub ${ }^{1}$ \\ ${ }^{1} \mathrm{HMC}$ NCCCR
}

September 11, 2020

\begin{abstract}
Background Obesity is a chronic disease that is increasing in prevalence in adults, adolescents, and children and it is now considered to be a global epidemic. Current recommendation for treatment of Chronic Myeloid Leukemia (CML) does not take in consideration the weight of the patient and doses ofTKIs
\end{abstract}

How I treat obesity and obesity related surgery in patients with chronic myeloid leukemia: an outcome of an ELN project.

Mohamed A Yassin ${ }^{1}$, Nancy Kassem² and Rola Ghassoub ${ }^{2}$.

1. Hematology Section, Medical Oncology, National Center for Cancer care and Research, HMC

2. Department of Pharmacy National center for cancer care and Research HMC.

Running title: CML and morbid obesity.

Novelty statement this the first proposed treatment algorithm of morbidly obese and obesity related surgeries in patients with chronic myeloid leukemia.

Corresponding Author:

Dr Mohamed A Yassin

Consultant Hematologists

Associate Professor of Medicine

National Center for Cancer Care and Research

College of Medicine, Qatar University

Doha Qatar

PO Box 3050

Yassinmoha@gmail.com

\section{Declaration:}

Ethics approval obtained from Hamad medical corporation IRB No MRC 01-18-337 and consents to participate were obtained from patients including consenting for publication

I confirm Availability of data and material

Authors declare no competing interests 
Funding publication : Self

Authors' contributions : Yassin MA concept writing editing Final approval of manuscript

NK writing editing and final approval of the manuscript

RG editing and final approval of the manuscript

Acknowledgements European Leukemia Net

\section{Hosted file}

How_Itreat_MORBID_OBESITY_version_final_3rd Sept 2020.docx available at https://authorea. com/users/324830/articles/479255-how-i-treat-obesity-and-obesity-related-surgery-inpatients-with-chronic-myeloid-leukemia-an-outcome-of-an-eln-project

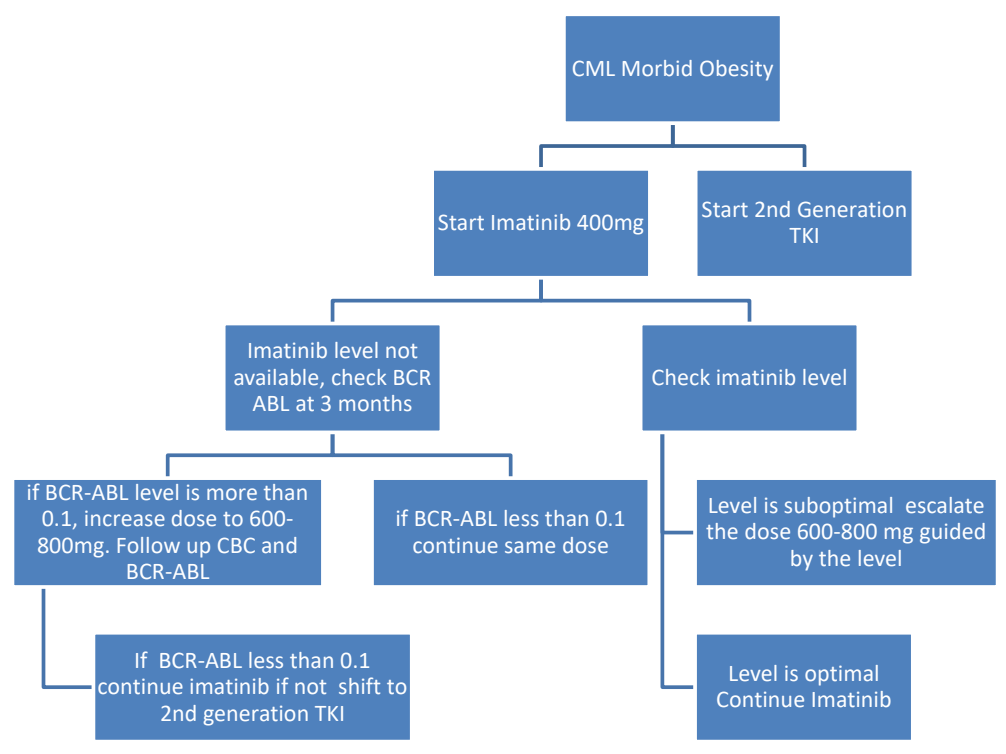

Figure (1) Imatinib as upfront for Morbid Obese patient with CML 


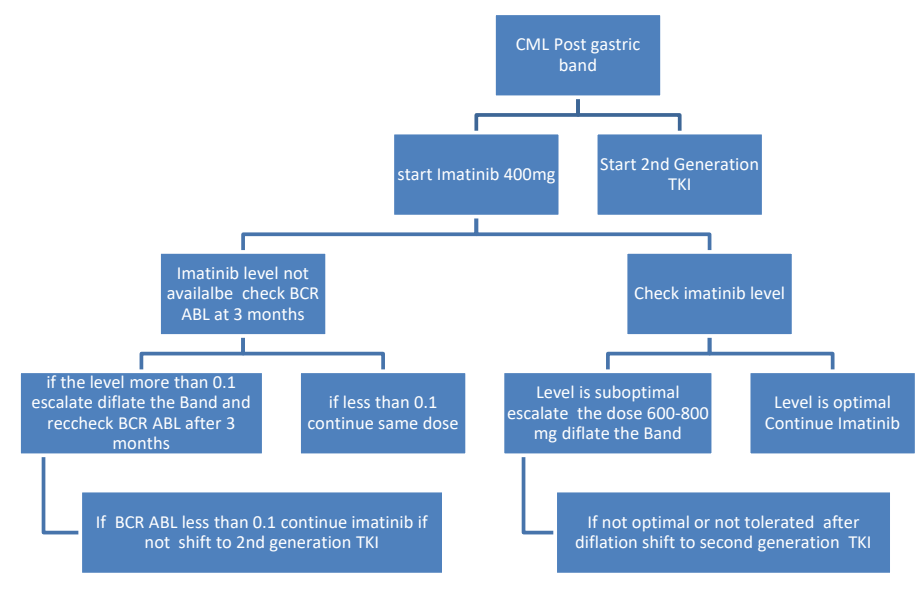

Figure (2) Imatinib post sleeve Gastrectomy 


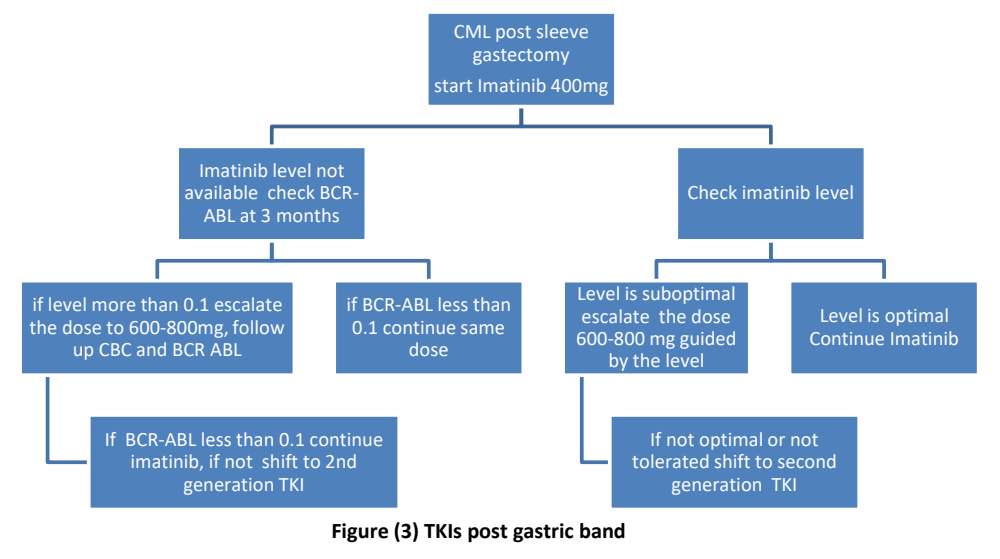

